\title{
Risk based decision making for evacuation in an uncertain world
}

\author{
Bas Kolen ${ }^{1,2, a}$ \\ ${ }^{1}$ HKV Consultants, Botter 11-29, 8232 JN Lelystad, Netherlands \\ ${ }^{2}$ Delft University of Technology, Mekelweg 2, 2628 CD Delft
}

\begin{abstract}
Evacuation is a possible response to the threat of flooding. However, evacuation can be costly with respect to time, money, and credibility. The decision-making process for mass evacuation is characterised by short reaction times and requires consideration of the probability of a certain impact, possible life-and-death situations and the economic impact. Evacuation can also reduce loss of life. However the frequency of evacuation-events is higher than flood-events because decisions are made on forecasts based on critical water levels which are less than the expected level of failure. A better understanding of heuristics and biases can improve judgments and decisions in cases of uncertainty. Authorities have to make a trade-off between the costs and possible benefits of evacuation when the disaster occurs. Decision makers (in multiple teams) and crisis managers can simultaneously provide multiple frames of reference about a certain phenomenon. This paper describes a decision support method and case study for The Netherlands for the use of "evacuation diagrams" to support decision makers (and crisis managers) to call for evacuation and the role of uncertainties.
\end{abstract}

\section{Introduction}

Floods are often described as the most deadly of all natural disasters [1]. Evacuation is a possible response to the threat of flooding. Worldwide events illustrate the possible results as well as the problems of evacuation. For example, during hurricanes and flooding, people and movable goods might be saved through evacuation [2].

The consequences of a flood event can be influenced by the strategy chosen for evacuation; a strategy is defined as a selection of measures to fulfil a defined objective. For example, in the case of a preventive evacuation in which all people must leave the area, the probability of car accidents and lack of fuel is far greater than when people remain in place. A decision made by the authorities will not automatically start to move people in a chosen direction, nor will it automatically prevent them from moving. Emergency systems, equipment and personnel will be available to implement decisions, but the capacity (defined as the number of means, personnel and infrastructure) or capability (defined as how these resources may be used and can be influenced by preparation) might not meet the required (or desired) level. Even when priorities are set, it can be questioned whether the available measures as foreseen during the planning can be implemented without failure. Many of these measures have not been tested during the actual circumstances of the event for low frequent disasters.

Evacuation can be costly with respect to time, money, and credibility [3]. Evacuation is defined as the process of alerting, warning, deciding, preparing, departing and (temporarily) holding people, animals, personal

\footnotetext{
${ }^{\mathrm{a} C o r r e s p o n d i n g ~ a u t h o r: ~ b . k o l e n @ h k v . n l}$
}

belongings and corporate stock and supplies from an unsafe location at a relatively safer location given the actual circumstances [4]. In this paper we focus on preventive evacuation in which people (attempt) to leave the area prior to a flood. When an evacuation begins too late, not all evacuees may be able to leave the area or arrive at a safe destination in time $[5,6,7,8]$. The response to Hurricane Katrina in New Orleans in 2005 demonstrated that people and goods that can be moved might be saved by preventive evacuation, but nonmovable goods will nonetheless be affected by the flood, and the economic processes will come to a halt [2]. The costs of evacuation due to hurricanes in the United States can exceed one million dollars per mile of coast as a result of losses in commerce and productivity as well as direct losses [9]. Credibility relates to concerns about the quality and sources of information, the discrepancy between timely warnings and later but more accurate warnings [10], and the impact of false alarms [11]. Authorities have to make a trade-off between the costs and possible benefits of evacuation when the disaster occurs [12].

\section{Dealing with uncertainties}

Research [13] shows in a survey that decision makers (and crisis managers) respond (very) different to the same information about flood risk and how to deal with uncertainties. This survey shows a wide variety between decision makers as well as a different value to risk (and in specific not risk averse) than used during the design of the system. This can cause delays in decision making 
because of disagreement among these decision makers. This can also cause, from the perspective of minimizing risk, 'wrong' decisions.

Uncertainties can be seen in the development of the event (the threat and consequences), the citizens' response, the response of all authorities spread over different (semi-public) organisations and the performance of physical infrastructure. A better understanding of heuristics and biases benefits decision making in uncertain situations [14]. This results in a better insight into the consequences of evacuation in certain circumstances and might result in other strategy choices. The definition of the types of uncertainties is subject to considerable debate in the literature [15]. A common distinction is made between the following [16]:

- The ontological nature of uncertainty is described as the inherent variability or unpredictability of the system. Examples are the development of the weather and a probability of a flood given a hydraulic load and strength of a levee.

- The epistemic nature of uncertainty is described as the imperfect knowledge about a system. Examples are the consequences of the citizens' response and calls for evacuation on the load of the road network.

Stakeholders as citizens and other governmental organisations, political leaders and emergency services, have different perspectives about the risk and have different objectives which influence their own choices. Each have to decide which information to use, and they have to assign value to information [17]. For authorities other sources of information besides the official situation reports are widely available from experts and the (social) media using their own perspective. Authorities can be divided in decision makers (officials who are responsible for the choices of teams inside an organisation or organisations as a whole) and crisis managers (officials who have a role in the crisis management structure) can simultaneously provide multiple frames of reference about a phenomenon. This is called ambiguity [16, 18; 19. In some literature ambiguity is described as uncertainty $[16,18]$. Other literature states that ambiguity is not a part of uncertainty but that 'Ambiguity is removed on the level of words by linguistic conventions' [19]. The risk of linguistic problems increases when the risk perception or awareness is limited. Because of the present on-going struggle for risk awareness for flood risk management by decision makers [20] and low risk perception of the public [21] ambiguity might impact decision making for evacuation.

This research describes the role of uncertainties in a risk-based decision model to support the planning and decision making process for evacuation in case of a threat of flooding as part of a flood risk approach.

\section{Methodology}

Risk is defined as the probability versus the consequences. This definition is commonly accepted in the flood risk literature $[2,22]$. Alternative definitions describe the risk in terms of hazard, vulnerability and exposure $[23,24]$. The hazard refers to the threatening natural event, including its probability of occurrence. Exposure and vulnerability relate to the consequences of an event. Vulnerability is broadly defined as the potential for loss [25], and exposure relates to the values, objects and people present within the area exposed to the hazard. Both approaches for defining risk lead to similar outcomes, as they both consider the occurrence of a hazard (the probability) and the consequences (vulnerability, exposure) of a given occurrence.

The valuation of human life is sometimes addressed as unethical. This is because a life is worth much more than its economic value, hence life is invaluable. Several fields of expertise relate decisions to the cost of loss of life [26]. A literature review [27] about the trade-off between money and fatality risks and discusses the use of the value of statistical life for policy decisions in the field of safety. It is shown that sometimes the value of statistical life is used implicitly, but examples are also provided of when this value is taken explicitly into account in policy guidelines in several countries. Other examples for the use of the statistical value for the loss of life are in the field of traffic management the monetary valuation of the prevention of a road crash fatality is defined for many countries [28]. In the health sector, for example, a benchmark is defined for a life in the UK [29]. The key driver for these investments is a risk-averse policy that aims to reduce the numbers of fatalities. However, it is clear that budgets for these investments are not infinite. Therefore, the implicit value of a human life is finite. Decisions about evacuation are made based on implicit trade-offs between the reduction of the risk for loss of life and the costs of these measures. The relationship between the costs of measures and the benefits of them feeds discussions about the need for these measures. Therefore, the use of a value for loss of life in quantitative cost-benefit analyses can offer insights into the effectiveness and costs of these measures.

\subsection{Deterministic decision making}

The model used in this paper is in detail described in [4] and based on cost benefit analyses. The costs are based on the economic damage and economic value of loss of life caused by preventive evacuation. The benefits are the reduction of the economic damage and economic value for loss of life into account in case of a flood (which is uncertain).

Based on a risk based a decision for evacuation has to be made when:

$$
P_{t}>\frac{s_{2} V+C_{2}}{\left(\left(s_{0}-s_{1}\right) V+C_{1}\right)}, \text { no evacuation when } P_{t}>1
$$

In which $P_{t}$ is the conditional probability of flooding given the forecasts of water levels and the strength of flood defences, $C_{1}$ as the value (Euro) of the goods that 
are saved by evacuation and $C_{2}$ as the costs (Euro) of the evacuation because of the limitations of economic and social processes and economic costs of the use of equipment and resources (this is estimated by the reduction of the added value to the gross regional product).

$s_{0}-s_{1}$ as the number of prevented loss of life by evacuation. $s_{1}$ is defined as the (persons) of lives lost in the case of a flood event with evacuation, $s_{0}$ is defined as the number (persons) of lives lost in the case of a flood event without evacuation. $s_{2}$ is the number of loss of life because of evacuation. $V$ is the economic value for loss of life.

\subsection{Probabilistic decision making}

The model presented in formula 1 is deterministic. In real life however decision makers are confronted with uncertain information about the probability of flooding, the costs and benefits of evacuation. Therefore the model of formula 1 is extended to a probabilistic model.

$P_{t, 1}$ describes the expected value of the conditional probability of flooding. However the forecasted water level and the strength of a levee is uncertain. $P_{t, 2}$ and $P_{t, 3 \text { value are the probability of flooding for a more }}$ extreme flood and a less extreme flood.

The number of loss of life in case of a flood depends on the size of a flood event as well as the available time for evacuation. In case of a more extreme flood event the expected loss of life (even with evacuation) is more than in case of a less extreme event.

$S_{0,1}$ is the expected number of lives lost in the case of a flood without evacuation for $P_{t, 1}, s_{0,2}$ for $P_{t, 2}$ and $s_{0,3}$ and $P_{t, 3}$. The number of lives lost in the case of a flood event with evacuation therefore depends on the effectiveness (given the size of the flood scenario) of this strategy. $s_{1,1}$ is the expected number of lives lost in the case of a flood event (taking the available time into account) with evacuation for $p_{t, 1}, s_{1,2}$ for $p_{t, 2}$ and $s_{1,3}$ for $p_{t, 3}$.

Parameter $S_{2}$ is assumed to be constant because the evacuation population does not depend on the decision for evacuation.

The value of goods that can be saved by evacuation $C_{1}$ depends on the size of the event as well, and the uncertainty can be taken into account in a probabilistic approach. $C_{1,1}$ is the expected number of lives lost in the case of a flood without evacuation for $p_{t, 1}, C_{1,2}$ for $p_{t, 2}$ and $C_{1,3}$ for $p_{t, 3} . C_{2}$ are related to the decision for evacuation and are assumed to be constant is this example. Therefore, the moment to decide for an evacuation with the objective to minimise loss of life should start when:

$$
P_{t}>\frac{s_{2} V+C_{2}}{\left(\sum_{q=1}^{3}\left(s_{1, q}-s_{0, q}\right) V p_{q}+\sum_{q=1}^{3} C_{1, q} p_{q}\right)}
$$

with no evacuation when $P_{t}>1$.

\subsection{Case study for The Netherlands}

A case study is applied for dikering 14 (central Holland) in The Netherlands. This dikering area is protected by flood defences against coastal flooding as well as river flooding.

$V=6,7 \mathrm{M} €[30,31]$ as used in risk assessments risk assessments made to upgrade the requirements for flood defences in The Netherlands [32, 33 34].

$S_{2}=25$ persons. Fatalities because of evacuation occur because of traffic accidents. Also it has been assumed that fatalities occur among people evacuated from hospitals because a significant part of Dutch hospitals have to be evacuated in a very short period of time.

$C_{2}=6,000 \mathrm{M} €$; the economic damage because of evacuation is related to the total Gross Domestic Product (590 Billion $€$ in 2010) of the Netherlands. Central Holland is the area with the highest economic value in The Netherlands. ). The costs of evacuation are estimated at $1 \%$ of the Gross Domestic Product assuming that economic processes will come to a stop for a week in half of the country.

For $C_{1}$ two alternative estimations are taken into account because of limited experience for The Netherlands. A high and a low value of the prevented damage because of evacuation equal to $10 \%(12,000 \mathrm{M} €)$ and $0,01 \%(12 \mathrm{M} €)$ of the economic damage of a worst credible flood. $C_{1,1}$ is equal to $C_{1}$. The value for $C_{1,2}$ is assumed to be $2 C_{1}$ and the value of $C_{1,3}$ to be $\frac{1}{2} C_{1}$.

Table 1 presents the estimations for loss of life in case of a flood and evacuation for different flood events. In case of a deterministic approach the consequences are used described for $p_{t, 1}$. 


\begin{tabular}{|c|c|c|c|}
\hline probability & \multicolumn{3}{|c|}{ loss of life } \\
\hline & Example 1 & Example 2 & \\
\hline$p_{t, 1}(60 \%)$ & $\begin{array}{c}S_{1,1}=4000 \\
\text { people }\end{array}$ & $\begin{array}{c}S_{1,1}=7800 \\
\text { people }\end{array}$ & $\begin{array}{c}S_{0,1}=8000 \\
\text { people }\end{array}$ \\
\hline$p_{t, 2}(10 \%)$ & $S_{1,2}=6000$ & $S_{1,2}=8900$ & $S_{0,2}=9000$ \\
& people & people & people \\
\hline$p_{t, 3}(30 \%)$ & $S_{1,3}=300$ & $S_{1,3}=600$ & $S_{0,3}=1500$ \\
& people & people & people \\
\hline
\end{tabular}

Table 1. Loss of life for different flood evens and the probability of these events.

The optimal conditional probability of flooding to call for evacuation in case of example 1 are presented in table 2 for a deterministic and a probabilistic approach, example 2 is presented in table 3 . It is shown that when less people can be saved by evacuation (example 2) evacuation is effective in in case of a higher conditional probability of flooding compared to the situation when more people (example 1) can be saved by evacuation.

The probabilistic approach is, by definition, more accurate than the deterministic approach because more possible events are taken into account assuming that the probabilistic information can be (subjectively) assessed. In case of the high value of $C_{1}$ the differences between a probabilistic and deterministic approach in $P_{t}$ is less than $5 \%$. Only in the case of a low value for $C_{1}$ and when relatively many loss of life can be prevented by evacuation the $P_{t}$ in case of a probabilistic approach is more than $10 \%$ higher than in case of a deterministic approach. Therefore, the need for this accuracy depends on the circumstances of the event and the value of economic goods and people that can be evacuated.

\begin{tabular}{|c|c|c|}
\hline & $C_{1}=12,000 \mathrm{M} €$ & $C_{1}=12 \mathrm{M} €$ \\
\hline $\begin{array}{c}\text { Deterministic } \\
\text { approach }\end{array}$ & $15,9 \%$ & $23 \%$ \\
\hline $\begin{array}{c}\text { Probabilistic } \\
\text { approach }\end{array}$ & $19,5 \%$ & $35,3 \%$ \\
\hline
\end{tabular}

Table 2. conditional probability of flooding to call for evacuation in case of example 1.

\begin{tabular}{|c|c|c|}
\hline & $C_{1}=12,000 \mathrm{M} €$ & $C_{1}=12 \mathrm{M} €$ \\
\hline $\begin{array}{c}\text { Deterministic } \\
\text { approach }\end{array}$ & $46.2 \%$ & No evacuation \\
\hline $\begin{array}{c}\text { Probabilistic } \\
\text { approach }\end{array}$ & $45.9 \%$ & No evacuation \\
\hline
\end{tabular}

Table 3. Conditional probability of flooding to call for evacuation in case of example 2.

\section{Concluding remarks}

This research presents a probabilistic decision support model for planning and decision making about evacuation in case of a threat of flooding. The model can support decision makers and given the costs and benefits of evacuation the optimal conditional probability of flooding can be defined to call for evacuation.

Because of the role of ambiguity and the lack of experience among decision makers with evacuation and flooding in many delta areas and specifically in the Netherlands where this is likely to occur, it is recommended to develop criteria which describe the required conditional probability of failure to call for evacuation. The parameters in the model are based on the parameters which are considered as most important by decision makers [13]. Therefore the model can be used to reduce ambiguity among decision makers and their advisors. The model offers a guideline to deal with statistics and uncertainty in case of a threat of flooding.

The model described in this paper does not take risk aversion into account. It is known that in case of a crisis the top priority of decision makers is to prevent loss of life. Risk aversion can be added to the model by introducing a factor that increases the value for loss of life.

A decision to evacuate before the onset of a disaster means that the decision makers will cause a crisis (an evacuation) to reduce the consequences of a potentially worse event (a flood). The case study shows that a call for evacuation is optimal when the probability of a flood is less than 1. This is of course obvious in most cases because evacuation reduces the consequences of a flood and, in general, the costs of evacuation are less. Criteria to activate emergency planning and different phases that indicate the status of the situation of flooding and mass evacuation are in many cases based on forecasts of water levels less than the level when failure is expected or in case of a probability of flooding. This implies as part of good planning the frequency of evacuation (because of a threat for flooding) is higher than the frequency of a flood. However an event of an evacuation not followed by a flood is often defined as a false alarm [11]. Decisions based on defined thresholds or structures taking uncertainties into account are not considered to be false, regardless of whether the flood occurs. A decision is only false when it is based on wrong information (e.g., forecasting models) or when procedures are not used correctly. 


\section{References}

1. Alexander D. (1993). Natural Disasters. UCL Press, London.

2. Vrijling JK. (2009). The lesson of New Orleans. in Kallen MJ, Kuniewski SP (eds). Risk and Decision Analysis in Maintenance Optimization and Flood Management. Pp. 57-69.

3. Bourque LB, Siegel JM, Kano M, Wood MM. (2006). Weathering the storm: impact of hurricanes on physical and mental health. Annals of the American Academy of Political and Social Science. 604:121-159.

4. Kolen B. (2013). Certainty of uncertainty in evacuation for threat driven responses; Principles of adaptive evacuation management for flood risk planning in the Netherlands. PhD Thesis University of Nijmegen.

5. Jonkman SN. (2007). Loss of life estimation in flood risk assessment. Theory and applications. PhD Thesis. Delft University of Technology.

6. Barendregt A, van Noortwijk JM, van der Doef M, Holterman SR. (2005). Determining the time available for evacuation of a dike-ring area by expert judgement. In Vrijling JK, Ruijgh E, Stalenberg B, Van Gelder PHAJM, Verlaan M, Zijderveld A, Waarts P (eds). International Symposium on Stochastic Hydraulics.

7. Urbina E, Wolshon B. (2003) National review of hurricane evacuation plans and policies: A comparison and contrast of state practices. Transportation Practices Part A 37:257- 275.

8. Kolen B, Helsloot I. (2012). Time needed to evacuate the Netherlands in the event of large-scale flooding: Strategies and consequences. Disasters, 36(4):700-722.

9. Wolshon B, Urbina E, Wilmot C, Levitan M. (2005). Review of policies and practices for hurricane evacuation, I: Transportation planning, preparedness, and responses. Natural Hazards Revie, 6:129-142.

10. Dow K, Cutter CL. (2000). Public orders and personal opinions: Household strategies for hurricane risk assessment. Environmental Hazards, 2:143-155.

11. Gruntfest EC, Carsell K. (2000). The Warning Process: Toward an Understanding of FalseAlarms.

12. Kolen B, Kok M, Helsloot I, Maaskant, B. (2013. EvacuAid: A Probabilistic Model to Determine the Expected Loss of Life for Different Mass Evacuation Strategies During Flood Threats. Risk Analysis, 33: 1312-1333.

13. Kolen, B. and Helsloot, I. (2014). Decision-making and evacuation planning for flood risk management in the Netherlands. Disasters, 38: 610-635

14. Tversky A. and Kahneman D. (1974). Judgment under Uncertainty: Heuristics and Biases. Science New Series, Vol. 185, 4157, 1124-1131.

15. Walker W.E., Harremoës, P., Rotmans, J., van der Sluijs, J. P., van Asselt, M.B.A., Janssen, P., Krayer von Krauss, M.P. (2003). Defining uncertainty. A conceptual basis for uncertainty management in model based decision support. Integrated Assessment, 4(1):517.

16. Brugnach M., Dewulf A., Pahl-Wostl C. and Taillieu T. (2008). Toward a Relational Concept of Uncertainty: about Knowing Too Little, Knowing Too Differently, and Accepting Not to Know. Ecology and Society, 13(2): 30 .
17. Boin A, 't Hart P, Stern E, Sundelius B. (2006). The politics of crisis management. Public leadership under pressure.

18. Dewulf A, Craps M, Bouwen R, Taillieu T, Pahl-Wostl C. (2005). Integrated management of natural resources: dealing with ambiguous issues, multiple actors and diverging frames. Water, Science and Technology, Vol. 52, pp 115-124.

19. Bedford T, Cooke R. (2001). Probabilistic risk analyses: foundations and methods. p19

20. ten Brinke W.B.M., Saeijs G.E.M., Helsloot I. and van Alphen J. (2008). Safety chain approach in flood risk management. Municipal Engineer, 161 (4):181 - 188.

21. Terpstra T. (2009) Flood Preparedness; Thoughts, Feelings and Intentions of the Dutch Public. Enschede: University of Twente.

22. ten Brinke WB.M., Bannink B.A., Ligtvoet W. (2008) The evaluation of flood risk policy in the Netherlands. Journal on Watermanagement, 151(4):181-188.

23. Kron, W. (2002) Keynote lecture: Flood risk = hazard $x$ exposure $\mathrm{x}$ vulnerability. In Proceedings of the flood defence conference.

24. Gendreau N, Longhini M, Combe PM. (1998). Gestion $\mathrm{du}$ risque d'inondation et méthode inondabilité: une perspective socio-economique. Ingenieurs EAT, 14:315.

25. Cutter S.L. (1996). Vulnerability to environmental hazards. Progress in Human Geography, 20 (4):529539.

26. Vrijling J.K., Gelder P.H.A.J.M. (2000). An analyses of the valuation of human life. ESREL.

27. Viscusie W.K., Aldy J.(2003). The value of a statistical life: a critical review of market estimates throughout the world. Journal of Risk and Uncertainty, 27 (1):5-76.

28. Rosebud. (2004). The use of efficiency assessment tools: solution to barriers.

29. HSE. (2011). Reducing risks protecting people, HSE's decision making process. Health and safety executive.

30. Bočkarjova M, Rietveld P, Verhoef E (2012). Composite valuation of immaterial damage in flooding: value of statistical life, value of statistical evacuation and value of statistical injury. Tinbergen institute discussion paper 12-047/3.

31. Bočkarjova M, Rietveld P, Verhoef ET. (2010) Instruments for decision-making: Immaterial damage valuation in flood risk context. In paper presented at the International Conference "Delta's in Times of Climate Change".

32. Kind J. (2011). Economic efficient flood protection standards for The Netherlands. 5th International Conference on Flood Management.

33. Jongejan R, Stefess H, Roode N, Horst W ter, Maaskant B (2011). The VNK2 project: A detailed, large scale quantitative flood risk analysis for the Netherlands. 5th International Conference on Flood Management.

34. De Bruijn K, Beckers J, Van Der Most H. (2010). Casualty risks in the discussion on new flood protection standards in the Netherlands. In de Wrachien D, Proverbs D, Brebbia CA, Mambretti S (eds). $2^{\text {nd }}$ International Conference on Flood Recovery, Innovation and Response. Pp. 73-83. 